\title{
Co-operation and Communication in Apes and Humans
}

\author{
INGAR BRINCK AND PETER GÄRDENFORS
}

\begin{abstract}
We trace the difference between the ways in which apes and humans co-operate to differences in communicative abilities, claiming that the pressure for futuredirected co-operation was a major force behind the evolution of language. Competitive co-operation concerns goals that are present in the environment and have stable values. It relies on either signalling or joint attention. Future-directed co-operation concerns new goals that lack fixed values. It requires symbolic communication and contextindependent representations of means and goals. We analyse these ways of co-operating in game-theoretic terms and submit that the co-operative strategy of games that involve shared representations of future goals may provide new equilibrium solutions.
\end{abstract}

\section{Co-operation}

Human beings as well as animals co-operate in order to reach common goals. There are many ways of co-operating, some of which may not merit being called 'co-operation' in the literal sense of the word. Among these one may count the more or less instinctive co-ordination of behaviour that emerges among ants building heaps or honeybees gathering food. On the opposite side of the scale, we find co-operation that builds on elaborate long-term planning and an open discussion of the means and the goal. In this article, we will compare and elucidate the similarities and differences between humans and apes as concerns co-operation. There is no doubt that apes co-operate, but, as we will argue, humans are able to do so in more flexible ways. Our aim is to spell out the crucial role of communication for different kinds of co-operation.

To co-operate is to work together for a joint benefit. A group of agents is co-operating when the agents together employ a certain means, or series of actions, to achieve a common goal. Co-operation can be achieved directly by a co-ordination of behaviour. It can also arise indirectly through a mutual sharing of representations of means and goal. It is vital for true co-operation that all the participants are actively involved. For instance, when a person manipulates other people in order to reach his goal, we do not say that the others are co-operating with him. This is the case even if the goal is of use to them all. Co-operation demands that all the

Thanks to Joëlle Proust, Bernhard Schroeder, and the participants of the seminar at LUCS for helpful comments. A shorter and in several respects different version of this paper has been published as 'Co-operation in Apes and Humans' (2003).

Address for correspondence: Ingar Brinck, Department of Philosophy, Lund University, Lundagård, SE-222 22 Lund, Sweden.

E-mail: ingar.brinck@fil.lu.se; peter.gardenfors@lucs.lu.se

Mind \& Language, Vol. 18 No. 5 November 2003, pp. 484-501.

(C) Blackwell Publishing Ltd. 2003, 9600 Garsington Road, Oxford OX4 2DQ, UK and 350 Main Street, Malden, MA 02148, USA. 
agents be in control of their own behaviour and actions in relation to the goal. Otherwise the agents will simply not be operating together, but one agent will be using the other agents as means to his ends.

Boesch and Boesch (1989, 2000) make a distinction between four kinds of co-operation, which is based on studies of the hunting behaviour of wild chimpanzees. The most advanced kind is the collaborative hunt in which the hunters perform different complementary roles directed towards the same prey. In the other kinds of hunt, the hunters all perform the same hunting movements. In a synchrony hunt, the hunters try to react to the actions of the other hunters in space and time, but an adjustment of behaviour is not necessary, while in a co-ordination hunt, the hunters do relate their actions in space and time. The cognitively least demanding kind is the similarity hunt, during which the hunters perform actions that are similar, though not related in space and time. The hunters do not consider the actions of one another, which means that co-operation is a contingent effect of the hunters' behaviour. Similarity hunt does not qualify as co-operation according to the definition we advanced above, since the hunters do not aim at acting together, but merely act on their own. The collected evidence on co-operation in hunting shows that collaborative hunting, which is the most advanced form, is frequently achieved by chimps, but also by wolves and lions, although this occurs less often. Collaborative hunting, in this sense, is thus not unique to primates (Boesch and Boesch-Achermann 2000, p. 186).

In all the kinds of hunting brought up by Boesch and Boesch, co-operation concerns the present, both in time and space. We will instead be focusing on the distinction between co-operation that occurs here and now and such that concerns the future. Future-directed co-operation requires planning ahead and thereby joint representations of things that do not yet exist. In many cases of co-operation, representations are not needed to stand in for the real thing, that is, for the means and the goal. If the goal is present in the actual context, for instance, water to drink, food to be had, or an antagonist to fight, it is not necessary to focus on a joint representation of it before taking common action.

But if, on the other hand, the goal is distant in time or space, then a shared goal representation must be produced before action can be taken. Humans have a powerful tool in language when it comes to creating shared representations of common goals. Language, as opposed to animal signalling, is not bound by the actual. It is based on the use of representations as stand-ins for actual entities. The use of representations replaces the use of environmental features in communication.

\section{Competitive versus Future-Directed Co-operation}

Co-operation is often competitive. It is undertaken by one group with the view to out-compete, or win over others. Co-operation may arise directly in competition about resources or as a response to threats. A group of apes may co-operate in order to defend themselves against a predator, or in order to get hold of some food from which the whole group will benefit. The group will normally be better off working 
together than if a solitary ape would have taken action. A group may also compete directly with another group.

In other cases, competitive co-operation can be indirect and involve several successive goals. For instance, one way to take the advantage over a particular rival is by forming an alliance or coalition with other individuals, as an intermediary to the ultimate goal of winning over the rival. In such a case, the agent first forms an alliance with another agent in relation to an immediate goal. This is a case of shortterm planning. However, the ultimate goal is to achieve an advantage over a third party. That is a case of long-term planning.

An example of how apes may engage in alliances is given in de Waal (1982). He describes how Yeroen, who had for a long time been the dominant male in the flock, was dislodged by Luik and later defeated by the young Nikkie. Instead of retiring, Yeroen formed an alliance with Nikkie. Together they defeated Luik, who had the sole right to the females. With the new ranking order-Nikkie at the top and Yeroen in second place-Yeroen could use his position to mate with some of the females. Nikkie could not protest with any vigour against this, since he was dependent on Yeroen's support in the struggle against Luik.

By our definition (excluding co-operation that emerges by chance as in Boesch and Boesch's similarity hunt) co-operation presupposes that each participant understands the target or goal of the other participants' actions, at least to the extent that they can try to relate their actions in time and space. When actions appear in a competitive context, whether the competition is within or between groups, apes have in general no difficulty in grasping their targets. One ape grasps why another ape performs a certain action, because the action is performed within the context of given and limited resources-food, partners, et cetera. The variables that are relevant in a certain situation are given by the shared context, and by having access to these the ape can interpret the action accordingly.

In contrast to competitive co-operation, which is concerned with resources that are present in the environment of the agents, future-directed co-operation occurs when the goal is not presently available and has not been available before. For instance, if there is a sudden food shortage in an environment that normally supports a particular group of agents, new strategies to survive must be developed by the group. The food that nevertheless is available may be used in a more efficient way, or migration to a new environment may be necessary. Then co-operating will not amount to a competition for given resources. Instead, the co-operation will concern a goal that has so far not been realised or does not yet exist.

The goals of future-directed co-operation are not part of an already existing pattern of co-operative behaviour in the group (or among different groups). Such goals do not receive their value by belonging to the set of entrenched, limited resources that the agents usually are competing for. When there is no established strategy for reaching a particular goal, its value will be difficult to determine. It has to be estimated with regard to possible outcomes in the future (cf. Morton, 2000). Apes cannot, it seems, engage in future-directed co-operation. One reason for this, we suggest, is that calculating the values of new and future goals demands cognitive resources that apes lack. 
Tomasello (1999, p. 36f) discusses the incapacity of apes to co-operate in ways that depend on collaborative learning. He traces this incapacity back to a lack of intentional teaching and imitative learning among apes. When an ape learns a behaviour from another ape, it will grasp that the goal is reached by a certain kind of instrumental behaviour performed in the presence of specific environmental conditions. But it will not pick up the particular technique and strategy that is used by the other ape. When the ape performs the action it has learnt, it will use an individual strategy, instead of reproducing and perhaps improving the exact technique of the teacher. This is, according to Tomasello, the reason why apes do not achieve the ratchet effect, that is, that they do not have a cumulative cultural evolution. They do not learn intentional strategies from each other, and they do not engage in role-taking. However, in human societies there is sociogenesis, during which something new can be created and shared within the culture through social co-operative interaction.

Our explanation of why apes do not achieve future-directed co-operation is not supposed to replace Tomasello's suggestion about the roots of collaborative learning, but may complement it. Our suggestion is that future-directed co-operation does not occur among apes, because it does not serve a given end in the context of action. Apes can only grasp the value of a goal if the goal has a fixed value. A goal acquires a fixed value for a group of agents by being firmly established in the existing behavioural patterns of the group. To have a fixed value the goal must exist as a resource in the environment of the agents (cf. Chalmeau, 1994). On the contrary, future-directed co-operation concerns goals that are not among the ones that are competed for in the normal case. Such co-operation is made possible by the capacity to imagine things without precedents. It requires detached, or context-independent, representations of means and goals. These representations will be further described in the next section.

In summary, apes co-operate in order to win something that is accessible to them, but not yet in possession. Humans can in addition co-operate in order to achieve something that is so far only desirable and not manifest and that does not have an entrenched, determinate value. The bases for the latter capacity will be fleshed out in the following sections.

\section{Means and Goals}

Agents co-operate when they together employ certain means to achieve a common goal. We maintain that the manner in which the agents represent the goal and the ways it can be reached will determine the nature of the co-operation that the agents can engage in. The actuality of the goal is of special interest for the present discussion.

Goals, say, food, can be characterised as either existing in the present (the ripe apples on the tree in front of you); not yet existing, but being expected and having precedents (the prey that will be hunted and then killed); or being novel and yet only possible (the idea of constructing a new kind of tool or weapon to later on hunt down the prey). Entertaining the last kind of goal requires that the agent can have a goal representation that is detached from the present context and also from previous contexts. 
Detached goal representations can be increasingly context-free: firstly, they can be independent of the time and place in which their real object or referent is situated, and secondly, they can be independent of having any referent at all (Gärdenfors, 1996; Brinck and Gärdenfors, 1999). In the latter case, they do not acquire their meaning by standing for some item that exists in the real world. Humans may imagine what is not there, and, moreover, make their imaginations known to each other. Apes, however, do not have detached goal representations (Gulz, 1991; Tomasello, 1999). Thus they are not capable of co-operating in order to reach a common goal that is neither present in, nor implicated by the immediate context (as the goal would be if, for instance, the ape had encountered similar goals previously).

It has been suggested that time displacement, that is, when the goal is delayed in time in relation to the actions, can result in detached representations of means or goal. But time displacement will not separate the goal from the original context. The reason is that the time displacement cannot by itself cause a change in means or goal, or in the way these elements are interrelated. It only pushes the context forward in time. The original context remains intact, except for its receiving a new time index. In contrast, detached goal representations emerge when a representation can be severed from its use in any particular kind of context.

Proust (2000) makes a distinction between three dimensions of thinking by relating thought to frames of reference. The frame of reference is the modality in which an agent deploys her representation of a given context. It can be the real world, a potential world, or a non-real, counterfactual state of affairs. Only in the last case does the agent represent the situation as part of a possible world that is distinct from the real world, one that she can compare with the real world. In contrast, when thinking occurs in the frame of reference of a potential world, the agent represents a future context token as analogous to a past one. She does not need to represent the future as distinct from the real world.

From what Proust says we can draw the conclusion that the capacity to entertain detached goal representations does not only consist in representing a goal independently of its original context. Moreover, this capacity involves a kind of counterfactual thinking by which the agent can reason across worlds to explore and evaluate the imagined situation as it might occur in the real world. If an agent has detached goal representations, but cannot relate them to the actual world, it will be impossible for her to implement them. They will be impotent.

The existence of imagined goals introduces a new type of complexity into cognition. If the goal is imaginary, its value is also imaginary. The goal does not constitute a stable resource, and its value cannot be calculated from known resources. This has consequences for co-operation. Much co-operative behaviour is compensatory - it is performed in exchange for other actions that have already been performed or are anticipated. Grooming, for instance, may be performed for the exchange of grooming itself or with the further end of getting support in future fights or alliances.

The exchange that underlies compensation presupposes that the resources are known, or at least can be known. But in the case of as yet imaginary goals, 
compensation becomes much more of a venture than a safe strategy. Furthermore, if expectations concerning future goals can be shared, the new goals will change the decision situation of the agents by bringing in new alternatives for action. If we view the interactions between the agents as a game, the new alternatives may radically change the optimal strategies of the agents. As a matter of fact, adding new alternatives can never make the decision situation worse for the agents, but may on the contrary increase their expectations considerably. In game-theoretical terms, the equilibrium set of actions may become totally different, when the future goals are accounted for. We will return to these issues in section 6, where we discuss co-operation in the light of game theory.

Similarly to goals, means can be characterised in different ways. While we characterised goals in terms of actuality, we describe means in terms of how they relate to their goal. Means can be invariably connected to a certain kind of goal. They can as well be variable, in case there are different means of reaching the same goal, or in case they by extension are used to reach several goals. Finally, they can be novel and original. Tomasello and Call (1997, p. 361) underline that in understanding behaviour as intentional, one understands that 'different means may be directed toward the same end and that the same means may be used for different ends'. As they see it, intentionality involves more than understanding that other agents can generate their behaviour spontaneously and that their behaviour is directed (1997, p. 203). It also involves an understanding of the structure of actions.

What is intentional about the capacity to separate means and ends? Intentionality, or goal-directedness, emerges as an ability to adopt the means to the situation at hand. To reach one and the same goal may require different means in different contexts. And the same means may afford different goals in different contexts. Intentional behaviour is flexible. It depends on the agent's ability to appreciate the distinctive character of each context he or she encounters. It also depends on the agent's ability to learn about new contexts and how to deal with them.

According to Tomasello and Call (1997), chimpanzees cannot represent the goal without the means to reach it. Goal and means form an indivisible whole. Humans, on the other hand, can reflect about different ways of reaching the goal. Since humans also can produce goals that do not yet have analogues in the environment, human co-operation has the potential of being very adaptable. The flexibility is double, because not only may means and goal vary, but there is also a variation between real and imagined means and goals.

\section{Co-operation and Communication via Joint Attention}

Co-operation depends on communication. Often communication can rely on display and signalling of the present and the next behavioural states, and does not even have to be intentional. Such exchange of information does not involve reference to objects in a shared environment. In other cases, though, the agents will not be able to co-ordinate their actions unless they can communicate their 
preferences and goals. They need to exchange information about the goal of the co-operation as well as about the means to reach it.

Moreover, co-operation usually stands in need of anticipation. For instance, Boesch and Boesch-Achermann (2000, p.173, pp. 238ff.) mention that a hunter needs to anticipate the next movement of the prey, as well as the future actions of the fellow hunters. When anticipation is called for, communication cannot simply rely on external, contextual cues that transmit information about the present state of affairs. In cases like these, joint attention may be useful, and even more so language. Language in particular has given human primates a great advantage as regards co-operation.

To explain how chimpanzees manage to anticipate the actions of conspecifics as well as of agents of other species, Boesch and Boesch-Achermann attribute abilities close to a theory of mind to the chimpanzees. They claim that attribution of intentions and competence to other agents is decisive for more advanced forms of co-operative hunting (p. 243). However, they also observe that the theory of mind of chimpanzees may not be identical to that of humans. Contrary to Boesch and Boesch-Achermann, we believe that the intentional behaviour of both humans and apes often can be explained without reference to a full-blown theory of mind that involves the attribution of beliefs to others, whether a human or a chimpanzee one. Joint attention, as described below, will do in many cases. As is argued in Gärdenfors (2003), theories of mind can be more or less advanced. Thus having a 'theory of attention' requires more limited cognitive capacities than having a 'theory of beliefs'.

Communication by signalling rests on a causal interaction between agents. Information can be transmitted causally by perceptual cues, which is sufficient to achieve competitive co-operation. The agents communicate by signalling their own states and action-readiness to each other by bodily behaviour. Co-operation sometimes does not need more than a chain of signals to issue in quite complex behaviour. The actions directly follow upon each other, because they causally prompt each other. For example, a flock of flying geese in a V-formation seem to be involved in fine-tuned co-operation, but the formation is actually caused by the aerodynamic forces which make the $\mathrm{V}$-formation the least strenuous for the geese.

Often co-operation is more elaborate. One reason for this is that perceptual cues of a certain type may prompt several kinds of behaviour. The appropriate behaviour is chosen with regard to the situation at hand and a particular goal. To produce the appropriate behaviour, the agents will have to check their mutual reactions to each other and the present situation. Consequently, for the co-operation to be successful in such cases the agents must engage in joint attention. Joint attention allows for two or more subjects to focus their perception simultaneously on a single object, provided that the subjects have focused on one another's attentional states beforehand (Bruner, 1998; Tomasello, 1999; Brinck, 2001). Joint attention is triadic; the agents do not only attend to a shared object, but also to the attention of each other. It involves eye contact, gaze following, and gaze alternation. 
Sometimes attention is directed only at the behaviour of other subjects. For instance, by looking at each other, two subjects can detect their respective objects of attention simply on the basis of the direction of their respective movements in combination with a salient object that functions as a target. Co-ordination of attention based on saliency and behavioural co-ordination will result in mutual object-focusing. An example of this is when animals together hunt prey that appear in flocks. By together attacking a single animal in the flock, the hunters are more likely to succeed than if they had each been attacking separate ones. This kind of joint attention, that is, mutual object-focusing, is sufficient for synchrony and co-ordinated hunts, as described by Boesch and Boesch (1989).

In contrast, fully-fledged joint attention is based on subject-subject attention and requires agents who actively seek goal-oriented information. The agents co-ordinate their attention by attending to each other as subjects that are capable of attending. This occurs, for instance, in complementary role-taking, when behavioural roles are intentionally distributed among the co-operating agents. Then the agents will on purpose take on different roles in order to achieve a common goal. Hunting in a group exploits complementary role-taking when the agents distribute the roles amongst themselves according to the part that each agent will play in catching the prey. Examples of roles are to go ahead of the others to locate the prey, to chase the prey from a particular direction or by a particular means, and to be the one who is supposed to finally kill the prey. Which kind of hunting will in fact emergesynchronic, co-ordinated, or such that requires complementary role-takingdepends primarily on the demands and constraints set up by the environment and the kind of prey that the group is hunting.

Distribution of roles as in complementary role-taking can emerge only if the agents are able to, by gaze, gesture, or other sorts of bodily behaviour, indicate the direction in which their objects of attention are found and also their own intentions to act. To be able to distribute actions during co-operation, the agents must be able to monitor each other's attention and actions, communicate or somehow display their own intentions, and sequence their behaviour in time around a mutually recognised theme. This behaviour is not fully developed until between 24 and 30 months in children (Brownell and Carriger, 1990). Boesch and Boesch-Achermann (2000, pp. 238ff.) claim that wild chimpanzees are capable of it.

Agents who are capable of subject-subject attention can attend to each other in a way that is not initiated and controlled by the object of attention. This means that attention-focusing may be guided by the agents' mutual attention to each other, instead of by what is happening around them. Thus the agents can attend in a goalintended way (Brinck, 2001). Goal-intention provides for the capacity to either direct or follow the attention of the other subjects in the absence of salient objects (though not in the absence of objects altogether). If, on the other hand, saliency is to guide the process that leads to joint attention, the object must be salient to all the agents, and presumably salient in a similar way to them all.

An example of a situation in which goal-intended attention is useful is when one agent wants to indicate a hidden object to another one. Suppose that there are 
some boxes in front of you, none of them especially salient. You want to indicate that one of these boxes is interesting, because you know that there is an object hidden in it. If your partner is not capable of detecting that you are attending in a goal-intended way, he will not follow your gaze to the box to which you are trying to direct him. The reason is that in the absence of salient objects, he will not react to your gaze as an expression of a directed attentional state.

One might think that joint attention necessarily involves having a theory of mind and being able to grasp that other subjects have mental states. But this is not the case. An agent can read the attention of other agents from their gaze together with behavioural cues (Gómez, 1994; Emery, Lorincz, Perrett, Oram and Baker, 1997). The awareness of states of attention relies on evidence about facial expression, gaze, and body posture, and their causal relations to action readiness and vigilance. Joint attention is primarily based on information laid out in the environment.

\section{Co-operation and Communication by Symbols}

If the desired goal is not present in the actual context of the agents, the processes of joint attention and attention reading will not suffice to communicate about it. In order to communicate about absent goals, the agents must be able to individually entertain detached representations, and then to attend jointly to these representations. This cannot be achieved by signalling or by joint attention, but symbolic communication is necessary. We submit that a major reason for the evolution of language is that it enhances co-operation. Language is the tool by which agents can make their imaginations, desires, and evaluations known to each other.

Tomasello (1998) describes symbols as social, inter-subjective, and bi-directional. Bi-directionality assures that a competent user who understands somebody else's use of a symbol as having a particular content can produce the symbol with that same content. Production and comprehension of symbols go together. Deacon (1996, 1997) explains how symbols acquire meaning by being related to each other in various ways such as by opposition, substitutability, and adjacency. Symbolic reference depends on indirect reference to objects, with the help of other symbols. The basis of the system is constituted by relations that hold between symbols, and not by relations between the symbols and the world.

It has so far not been shown that apes can communicate in a fully symbolic way (Deacon, 1997; Tomasello, 1999). On the contrary, it seems that apes in their natural habitat, which have not received training, mainly exploit indexicals in sign communication. That means that the signs which the apes use acquire their meaning by standing in a contiguous, causal, and contingent relation to what these signs are about. Indexicals are dependent on the context of use for their meaning. They stand in contrast to symbols, which retain their meaning across contexts.

Thinking in symbols sets the agent free from the desires imposed by the actual context. For instance, it may be hard to give up a utility in possession for a future, 
but more precious one. The reason is that the present utility seems much more valuable than the imagined one. It has been shown that apes that have been trained to use symbols to think and communicate instead of using the things themselves (as in indication) are able to plan for future needs and do not give in for the present ones.

This is illustrated by an experiment with chimpanzees performed by Boysen and Berntson (1995). They put peanuts in two heaps of different sizes placed on a table out of reach of the apes. One ape was to point at one of the heaps, and then that heap was given to the other ape, while the first ape got the one that he did not point at. The result of the test was surprising. The first ape repeatedly pointed at the biggest pile and was disappointed when that pile was given to the other one, and he himself received the small pile.

The chimpanzees consistently chose the bigger pile of food. The presence of the desired food seems to make them incapable of imagining the recurring near future when the other party receives the pile that they choose, and they are left with the smaller pile. Boysen and Berntson's experiment clearly shows how difficult it is to manage even the simplest form of planning for a future goal. Deacon (1997, p. 414) writes that the choice is difficult for chimpanzees, because the indirect solution (choosing the small pile) is overshadowed by the direct presence of a more attractive stimulus, namely, the big pile. They cannot suppress the emotions that are evoked when they perceive the big pile. If one performs the same kind of experiment with human children, they have no problem choosing the small pilefrom the age of two and up. These children can imagine receiving the big pile when they point at the small one. When children are younger, their behaviour is similar to the chimpanzees'.

The chimpanzees in Boysen and Berntson's study were also trained to connect numerals with quantities, so that they knew that the figure 5 corresponded to a bigger pile of sweets than the figure 3 . Once they had learned the meaning of the numerals, they were instead allowed to choose between two cards showing numerals, and the pile corresponding to the selected numeral was given to the other chimpanzee, while they themselves received the pile corresponding to the numeral they had not chosen. The results were now better: They could learn to select cards so that they received the big pile. The explanation is that there is no longer a conflict between the symbols they see and what they have to choosethe cards have no intrinsic value for the chimpanzees.

Why is it cognitively more difficult to plan for future needs than for current ones? The answer has to do with the different representations that are required for the two types of planning. When planning in order to satisfy current needs, the agent must be able to represent the actions and their consequences, and to determine the value of these future consequences in relation to the needs he has at that very moment. But no separate representation of the need itself is required. On the other hand, to plan for future needs, the agent must also be able to represent the potential needs (and to understand that some of them in fact will arise). The available ethological evidence so far indicates that man is the only species of animal with the ability to imagine future wishes and to plan and act 
accordingly (Gulz, 1991). Deacon (1997) calls our thinking front-heavy; anticipatory planning takes place in the frontal lobe, the most recently evolved part of the brain.

It has been suggested that communication by icons, for instance, by miming, constitutes an intermediary step between indexical and symbolic communication (Donald, 1991). This suggestion seems correct at least as concerns communication about the means to reach a goal. By using icons, one agent can show another how to act in order for the two of them to reach a common goal. Using icons that are not conventionalised, nor constitute behavioural routines, to communicate requires that one can entertain an explicit communicative intention. More specifically, it requires that one is able to pick out a way to visualise one's thoughts by gesturing. The gesture must also be recognisable to the others. Moreover, grasping the purpose of somebody else's use of an icon, that is, the function that the icon is meant to perform, requires that one can perceive or 'read' the intention behind the behaviour that constitutes the icon. Finally, the agent must understand how the intentional states of other agents are related to his or her own states and actions. If all these conditions are satisfied by a group of two or more agents, it then seems that an icon can work as an imperative, urging the agents to 'Do like this!'.

In a series of experiments Povinelli and O'Neill (2000) show that chimpanzees do not spontaneously use gestures to instruct each other, for instance, to direct the behaviour or attention of the other. In the experiments, an experienced chimpanzee and a naive partner face a problem that requires co-operation to be solved. The problem is to pull in a box baited with food that is too heavy for a single animal to move. In the experiments, the experienced chimpanzee used neither solicitation, nor physical manipulation to instruct his partner (also cf. Chalmeau (1994) and Chalmeau, Visalberghi and Gallo (1997)). Notice that the animals did not have behavioural routines or conventionalised behaviours that otherwise might have been deployed to influence each other. One conclusion from these experiments seems to be that chimpanzees cannot use icons to facilitate co-operation. The reason for this may be that they cannot entertain the set of intentions mentioned above.

Using icons may be a way of distributing actions during co-operation that requires complementary role-taking and that concerns an activity, which is not well entrenched-as opposed to the kind of complementary role-taking that was described in connection with chimpanzee hunting. In the latter case, icons are not needed to introduce new actions into the group, since the roles that are used during hunting already are known to all the agents or at least available within the group. Nevertheless, it appears that icons cannot be used to express new types of goals with which the agents (except the one introducing it) are not, not even remotely, acquainted. The reason is that iconic meaning arises from a similarity relation between the icon and what it depicts. Understanding what the icon means requires that one is familiar with its referent. Consequently, the use of icons to introduce new behaviour in a group would not be as efficient as it at first glance might seem. 
Symbolic communication paves the way for long-term co-operation and for co-operation towards as yet unrealised, perhaps indeterminate, future goals. Say that an agent wants to introduce the idea of constructing a defence wall around the camp to increase security and protect from unknown dangers. The idea of building such a wall cannot be communicated to the other agents by icons, if the wall constitutes a new type of goal without precedents. Symbolic communication is necessary for communicating the idea. Language gives humans an enormous advantage concerning co-operation in comparison to other species. We view this advantage as a strong evolutionary force behind the emergence of symbolic communication.

Humans can co-operate even when the desirable goal is remote from the conditions set by the environment. Since humans can have detached representations of both means and goals, and also can separate representations of means from goal representations, the possibilities for future-directed co-operation that this opens up are extensive. The environmental conditions can be completely transformed in order to give way for the means considered necessary to produce or realise an imaginary goal.

Human beings have often used such tactics in history. Whole landscapes have been not only transformed, but even created from scratch to make room for new inventions and the realisation of new desires. One recent example is the capital of Brazil, Brasilia that was built in the end of the 1950s by Costa and Niemeyer. The design of the city was guided by a vision of a modern and technologically based future. Another example is the artificial irrigation that has made possible agriculture in desert landscapes, and yet another one the construction of water pools or reservoirs to either exploit or change the reaches of rivers.

To show the evolutionary importance of co-operation for future goals, Deacon (1997) suggests that the first form of symbolic communication is marriage agreements. The ecological conditions of the early hominids made meat a prominent part of their diet. At the same time, a nursing female hominid, with a baby that is much more dependent on its mother than those of the other apes, cannot efficiently participate in hunting and scavenging. A female who cannot count on at least one male supplying her with meat will suffer from a high probability of losing her children. On the other hand, a male who cannot be reasonably sure that he is the father of the children he is helping runs a serious risk of investing in the genes of other males.

Deacon (1997, p. 399) argues that for these reasons there was strong evolutionary pressure in hominid societies to establish relationships of exclusive sexual access. He says that such an exclusive sexual bond is a prescription for future behaviors'. A symbolic pair-bonding relationship implicitly determines which future behaviours are allowed and not allowed. These expectations concerning future behaviours do not only include the pair, but also the other members of the social group who are supposed not to disturb the relation by cheating. Anybody who breaks the symbolic agreement risks punishment from the entire group. 


\section{Competitive and Future-Directed Co-operation in Game Theory}

In section 2, we introduced two concepts of co-operation. Competitive co-operation is undertaken with the aim to win over others. The goal of the co-operation has a fixed value, because it is a limited resource competed for by a group or groups of agents. Cost-benefit analyses can be used to choose a strategy for reaching the goal. It is often assumed that tacit cost-benefit analyses underlie competitive co-operation among animals. For instance, Boesch and Boesch-Achermann (2000, Ch. 8) analyse the costs and benefits of taking different roles in co-operative hunting.

Future-directed co-operation occurs when the end that is pursued is not well entrenched. In this case, which value the goal will receive will depend on if the agents can extend the existing pool of goals and values by adding the new goal to it, or if a completely new value structure will have to be created around it. The new value structure may not, at least not initially, be accessible for all agents in the group. Possibly, only those agents who were introducing the goal have all the information about it.

Future-directed co-operation requires communication about detached representations, while the communication required by competitive co-operation works with indexical ones. The communicative skills demanded by competitive co-operation are less demanding than those demanded by future-directed co-operation. In this section we will analyse the two kinds of co-operation in game-theoretic terms. We claim that the capacity to communicate about detached representations will turn co-operative situations of the prisoner's dilemma type into situations with an equilibrium solution.

In classical game theory, a strict partitioning between co-operative and nonco-operative games is made. A game is said to be co-operative if the players have full information about each other's choices, while it is said to be non-co-operative if they have no information whatsoever about the other players' choices. However in real life, the two extremes of co-operation and non-co-operation are rarely attained. In most cases a player has only partial information about the choices and potential behaviour of his opponents, which either results from memories of earlier, similar situations (for instance, in iterated games) or is a consequence of other kinds of expectations.

As a paradigm case of how different kinds of co-operation affect a game situation, let us look at how various kinds of information about the other players affect choice situations of the prisoner's dilemma (PD) type. In a PD game, the players have two options - to co-operate or defect. The outcomes are such that your best individual strategy is to defect, independently of whether the other players co-operate or defect. However, if all players defect, the outcome is much worse than if everybody co-operates.

If the $\mathrm{PD}$ is seen as a purely co-operative game, traditional game theory prescribes the co-operative strategy as the only rational one for all players. In 
contrast, in a purely non-co-operative PD, the theory claims that defecting (the non-co-operative strategy) is the only rational strategy.

It turns out that in real situations where the game is described as a nonco-operative one, human subjects (and animals) often choose the co-operative strategy, in contrast to what is recommended by game theory (Axelrod, 1992). In our opinion, the reason for this seeming irrationality is that a PD type situation is seldom treated as a strictly non-co-operative game. Even if a subject does not have any real information about her opponents' choices in the situation, she has expectations about their behaviour. For example, she may count on them reasoning in the same way as she does herself, or that they would, like herself, feel ashamed if they chose the defecting strategy.

Such expectations function as information about the choices of the others that effectively make the game situation partly co-operative. In such a situation, the rational move to make may very well be to co-operate. Since it is hard to imagine a game situation where a human player has no expectations whatsoever about the opponents, it is questionable whether the pure non-co-operative situation prescribed in game theory can ever be attained.

In experiments with iterated versions of the PD, animals as well as humans tend to choose strategies that result in mainly co-operative solutions (Axelrod and Hamilton, 1981; Axelrod, 1984; Riolo, Cohen and Axelrod, 2001). A popular strategy in iterated two-person PD games is 'tit-for-tat', which means that you start by co-operating and then choose whatever option your opponent chose in the preceding game. In iterated games, the expectations are formed by learning from earlier game situations. Animals with comparatively limited cognitive capacities can attain this kind of learning. In some cases, the co-operative strategy can even be genetically determined (Axelrod and Hamilton, 1981).

Co-operative hunting is basically a PD game. Co-operating means taking part in the hunt, while defecting means trying to benefit from the gain without hunting yourself. As Boesch and Boesch-Achermann (2000, pp. 175ff.) describe, defecting is a real problem for chimpanzee hunting. The question is how co-operative hunting can remain stable at all. It seems that different chimpanzee populations have developed different social strategies to overcome the PD situation. Among the chimpanzees in the Tai forest, members of the hunting group adjust the amount of meat an individual receives according to its contribution to the hunt. Since the quantity of meat that an individual hunter can expect increases from solitary hunting to group hunts with three or four participants, the apes have a strong incentive to take part in group hunting (Boesch and Boesch-Achermann, 2000 , pp. 175-176). Even though defecting still is rather frequent, the gain obtained by the collaborators is large enough to maintain the co-operative strategy. In contrast, it seems that in other chimp populations collaborative group hunting is less frequent. The reason may be that in these societies the social strategies that prevent the defecting strategy are much weaker.

Another factor that influences the choice situations in PD type games is that among social animal species, and humans in particular, the possibility of sanctions 
from the rest of the group may drastically change the game situation. Morton (2000) gives an example of how the presence of potential sanctions can solve a PD in an evolutionary context. Two proto-humans are considering whether to fight over a carcass or share it. The structure is that of a PD type game. If one of them is pacific, then the other will beat him. So they will both fight, though each would have preferred a peaceful division of the carcass. But then introduce a third party into the game, a patriarch who, if he hears a quarrel, will interfere and take anything that is worth having. Now if the two proto-humans behave in a way that will catch the patriarch's attention, and refrain from fighting or sneaking (both of which would put them in the original PD situation), then they can share the carcass without the patriarch's interfering.

The complex action that the two agents together perform arises from expectations about the third party's behaviour. It is a stable equilibrium. This strategy became possible because the presence of the patriarch changed the values of the available options. Then the defection strategy to the PD could be avoided.

Even if you temporarily gain by defecting in a (non-iterated) PD situation, the risk of being punished by the peers in the group for such a non-co-operative (egoistic) behaviour should be taken into account when calculating the utilities of the available strategies. If the punishment is severe and the risk of receiving it high enough, the payoffs of the game will change in such a way that it no longer is a PD, but a game where the only rational strategy is to co-operate (cf. Morton 2000). Consequently, including expectations about sanctions is a way of changing the rational equilibrium of a PD type game into a game with only a co-operative equilibrium.

As a side remark, shame is likely to be a bodily reaction that expresses an expectation of scorn or punishment, the function of which is precisely to alter the expected utilities in a PD game situation, where one is tempted to defect. It is possible that shame and its associated behaviours have evolved in order to change the perceived outcomes from a PD situation into a game where the co-operative strategy is favoured.

In line with the general tenet of this paper, we claim that the capacity to share detached representations of a future goal will change a situation, which would be a PD without this capacity, into a game where the co-operative strategy is the equilibrium solution. For example, if we live in an arid area, each individual (or family) will benefit by digging a well. However, if my neighbour digs a well, I may defect and take my water from his well, instead of digging my own one. But if nobody digs a well, we are all worse off than if everybody does so. This is a typical example of a PD.

Now if somebody communicates the new idea that we should co-operate in digging a communal well, then such a well, by being deeper, would yield much more water than all the individual wells taken together. Once such co-operation is established the PD situation will disappear, since everybody will benefit from achieving the common goal. In game-theoretical terms, digging a communal well will be a new equilibrium strategy. This example shows how the capacity of 
sharing detached goal representations in a group can strongly enhance the value of co-operative strategies within the group. The upshot is that strategies based on detached goal representations may introduce new equilibria that are beneficial for all participants.

As mentioned above, the problem is that in future-directed co-operation, the goal may be without any precedent, like the communal well in the example. If the goal is in this sense imaginary, its value will be so too. It will be difficult to make estimates concerning the behaviour of the other agents on the basis of previous experience, since the situation is new and unknown. In this case, the individual players will have to change the general structure of their expectations to accommodate the new situation.

Therefore, the capacity to communicate about detached representations will be crucial for improving the strategic situation of the group. In the example of the communal well, communication via joint attention will not work, since there is no well to attend to. In such cases, symbolic communication is essential. However, it is not sufficient to communicate the plan for a well of an unknown type, but the community should also be convinced of the value of the well. This is where persuasion enters the scene-those who have a talent for convincing other agents that a common, future goal is valuable have a better chance of driving through the co-operation.

\section{Department of Philosophy and Cognitive Science Lund University}

\section{References}

Axelrod, R. 1984: The Evolution of Cooperation. New York, NY: Basic Books.

Axelrod, R. 1992: The evolution of strategies in the iterated prisoner's dilemma. In C. Bicchieri, R. Jeffrey and B. Skyrms (eds.), The Dynamics of Norms. New York: Cambridge University Press.

Axelrod, R. and Hamilton, W.D. 1981: The evolution of cooperation. Science, 211, 1390-1396.

Boesch, C. and Boesch, H. 1989: Hunting behaviour of wild chimpanzees in the Taï National Park, Ivory Coast. American Journal of Physical Anthropology, 78(4), 547-574.

Boesch, C. and Boesch-Achermann, H. 2000: The Chimpanzees of the Tai Forest: Behavioural Ecology and Evolution. Oxford: Oxford University Press.

Boysen, S. and Berntson, G. 1995: Responses to quantity: perceptual versus cognitive mechanisms in chimpanzees (Pan troglodytes). Journal of Experimental Psychology and Animal Behaviour Processes, 21, 82-86.

Brinck, I. 2001: Attention and the evolution of intentional communication. Pragmatics \& Cognition, 9(2), 255-272.

Brinck, I. and Gärdenfors, P. 1999: Representation and self-awareness in intentional agents. Synthese, 118, 89-104. 
Brinck, I. and Gärdenfors, P. 2003: Co-operation in apes and humans. In C. Chakravarti, M.K. Mandal and R.B. Chatterjee (eds.), On Mind and Consciousness. Selected papers. MICON2002. Shimla: Indian Institute of Advanced Studies, 365-376.

Brownell, C.A. and Carriger, M.S. 1990: Changes in co-operation and self-other differentiation during the second year. Child Development, 61, 1164-1174.

Bruner, J. 1998: Routes to reference. Pragmatics \& Cognition, 6, 209-227.

Byrne, R.W. and Whiten, A. (eds.) 1988: Machiavellian Intelligence: Social Expertise and the Evolution of Intellect in Monkeys, Apes, and Humans. Oxford: Oxford University Press.

Chalmaeu, R. Visalberghi, E. and Gallo, A. 1997: Capuchin monkeys, Cebus apella, fail to understand a cooperative task. Animal Behavior, 54, 1215-1225.

Chalmaeu, R. 1994: Do chimpanzees cooperate in a learning task? Primates, 35, 385-392.

Deacon, T. 1996: Prefrontal cortex and symbol learning. In B.M. Velichkovsky and D.M. Rumbaugh (eds.), Communicating Meaning: The Evolution and Development of Language. Mahwah, NJ: Lawrence Erlbaum.

Deacon, T. 1997: The Symbolic Species: The Co-evolution of Language and the Human Brain. Cambridge, MA: MIT Press.

Donald, M. 1991: Origins of the Modern Mind. Cambridge, MA: Harvard University Press.

Emery, N.J., Lorincz, E.N., Perrett, D.I., Oram, M.W. and Baker, C.I. 1997: Gaze following and joint attention in Rhesus Monkeys (Macca mulatta). Journal of Comparative Psychology, 111(3), 286-293.

Gärdenfors, P. 1996: Cued and detached representations in animal cognition. Behavioural Processes, 36, 263-273.

Gärdenfors, P. 2003: How Homo Became Sapiens: On the Evolution of Thinking. Oxford: Oxford University Press.

Gómez, J.C. 1994: Mutual awareness in primate communication: A Gricean approach. In S.T. Parker, R. Mitchell, and M. Boccia (eds.), Self-Awareness in Animals and Humans. Cambridge: Cambridge University Press.

Gómez, J.C. 1998: Some thoughts about the evolution of LADS, with special reference to TOM and SAM. In Carruthers, P. and J. Boucher (eds.), Language and Thought. Cambridge: Cambridge University Press.

Gómez, J.C., Sarria, E., and Tamarit, J. 1993: The comparative study of early communication and theories of mind: Ontogeny, phylogeny, and pathology. In S. Baron-Cohen, H. Tager-Flusberg, and D.J. Cohen (eds.), Understanding Other Minds. Perspectives from Autism. Oxford: Oxford University Press.

Gulz, A. 1991: The Planning of Action as a Cognitive and Biological Phenomenon. Lund: Lund University Cognitive Studies 2.

Morton, A. 2000: The evolution of strategic thinking. In P. Carruthers and A. Chamberlain (eds.), Evolution and the Human Mind: Language, Modularity and Meta-Cognition. Cambridge: Cambridge University Press.

Povinelli, D.J. and O'Neill, D.K. 2000: Do chimpanzees use their gestures to instruct each other? In S. Baron-Cohen, H. Tager-Flusberg, and D.J. Cohen (eds.), Understanding Other Minds. Perspectives from Autism. Oxford: Oxford University Press. 
Proust, J. 2002: Can 'radical' simulation theories explain psychological concept acquisition? In J. Dokic and J. Proust (eds.), Simulation and Knowledge of Action. Amsterdam: John Benjamins, AiCR.

Riolo, R.L., Cohen, M.D. and Axelrod, R. 2001: Evolution of cooperation without reciprocity. Nature, 414, 441-443.

Tomasello, M. 1996: Do apes ape? In J. Galef, and C. Heyes (eds.), Social Learning in Animals. The Roots of Culture. New York, NY: Academic Press.

Tomasello, M. 1998: Reference: Intending that others jointly attend. Pragmatics $\mathcal{E}$ Cognition, 6, 229-243.

Tomasello, M. 1999: The Cultural Origins of Human Cognition. Cambridge, MA: Harvard University Press.

Tomasello, M. and Call, J. 1997: Primate Cognition. New York, NY: Oxford University Press.

Waal, F. de 1982: Chimpanzee Politics. London: Jonathan Cape. 